\title{
Factors Affecting Utilization of Voluntary HIV Counseling and Testing Services among Teachers in Awi Zone, Northwest Ethiopia
}

\author{
Woudneh Gereme Desta, ${ }^{1}$ Mulusew Alemneh Sinishaw, ${ }^{2}$ and Kelemu Dessie Bizuneh ${ }^{3}$ \\ ${ }^{1}$ Health Promotion and Disease Prevention Core Process, Amhara National Regional State Health Bureau, Bahir Dar, Ethiopia \\ ${ }^{2}$ Clinical Chemistry, Amhara Public Health Institute, Bahir Dar, Ethiopia \\ ${ }^{3}$ Public Health Emergency Management, Awi Zone Health Department, Injibara, Ethiopia
}

Correspondence should be addressed to Mulusew Alemneh Sinishaw; mulusewalemneh@yahoo.com

Received 29 November 2016; Revised 16 March 2017; Accepted 5 April 2017; Published 23 April 2017

Academic Editor: Soraya Seedat

Copyright (C) 2017 Woudneh Gereme Desta et al. This is an open access article distributed under the Creative Commons Attribution License, which permits unrestricted use, distribution, and reproduction in any medium, provided the original work is properly cited.

HIV/AIDS affects the basic educational sector which is the most productive segment of the population and vital to the creation of human capital. The loss of skilled and experienced teachers due to the problem is increasingly compromising the provision of quality education in most African countries. The study was proposed to determine the magnitude of VCT utilization and assess contributing factors that affect VCT service utilization among secondary school teachers in Awi Zone. A cross-sectional study design was conducted among 588 participants in 2014. Self-administered questionnaire was used to collect data. Data was analyzed using SPSS version 16, presented as frequencies and summary statistics, and tested for presence of significant association with odds ratio at 95\% CI. More than half (53.6\%) of study participants were tested for HIV. Those who had sexual intercourse, had good knowledge about VCT, were divorced/widowed, were in the age group of 20-29 years, and were married utilized VCT services two, three, four, three, and two times better than their counterparts, respectively. Actions targeting unmarried status, increase of educational level, and teachers with age groups above 30 years are necessary to follow their counterparts to utilize VCT service in order to save loss of teachers.

\section{Introduction}

Assumption of Human Immunodeficiency Virus/Acquired Immune Deficiency Syndrome (HIV/AIDS) as a serious health crisis in the past few decades shifted to its impact on social and economic structures especially of developing countries as it affects adult populations in the productive and reproductive age groups [1].

HIV/AIDS epidemic stage was reached globally at different times according to different risk factors that undermine general productivity and production of the household as well as community, scrotal, and national economic securities is being affected [2].

According to UNAIDS report on the global AIDS epidemic in 2010, globally in 2009 about 33.3 million people (2.5 million children) were living with HIV/AIDS; among these 2.5 million people are newly infected with the virus; in the same year 1.8 million people $(260,000$ children less than 15 years) died due to HIV/AIDS [3].

Sub-Saharan Africa remains hardest hit and has just over $10 \%$ of the world population but is the home of 24.7 million people (1.5 million new infections) living with HIV/AIDS. Sub-Saharan Africa constituted $71 \%$ of people living with HIV/AIDS in the world; among these women are more affected than men; at the same time 1.1 million people lost their life as a result of HIV/AIDS [3, 4].

Ethiopia is one of the highly affected countries with HIV/ AIDS pandemic in the world. Since the first two reported AIDS cases in 1986, the disease has spread at alarming rate throughout the country [5].

Eastern African country Ethiopia was a home of 1,116,216 people (336,160 were eligible for antiretroviral treatment (ART)) living with HIV/AIDS out of which 72,945 (20,522 needed ART) were children less than 15 years. Due to the 
combined effect of poverty and HIV/AIDS, more than 5.4 million children under the age of 18 years were orphaned, out of which $855,720(16 \%)$ lost at least one parent due to HIV/AIDS [6].

Different professionals are victims for HIV/AIDS disease in all sectors; particularly the basic education sector which is vital to the creation of human capital is also equally affected. The loss of skilled and experienced teachers due to HIV/AIDS related deaths and long term HIV/AIDS related illnesses are affecting the provision of quality education in most African countries [7].

The impact of HIV/AIDS in education sector causes multifaceted effect. Evidence obtained in 1998-2003 among teachers in Addis Ababa showed that HIV/AIDS related illnesses were the leading cause of death accounting for half of all mortalities [8].

Since the issue not only is a health concern, but also has social, economic, and political implications, the Federal Ministry of Health has undertaken various appropriate reversing measures [9]. One strategy for prevention and control of HIV/AIDS is provision of extensive voluntary HIV counseling and testing services.

Voluntary HIV counseling and testing is the process by which an individual undergoes counseling enabling him or her to make an informed choice about being tested for HIV [1]. Voluntary HIV counseling and testing allows teachers to know their HIV serostatus and, if the result is positive, prepare for treatment as well as care and support services [10].

Many people in Ethiopia living with HIV/AIDS do not know their serostatus including teachers. Various studies undertaken in Ethiopia have shown different factors that contributed to nonacceptance of voluntary counseling and testing (VCT) services; among these factors are lack of perception of being at risk, no consideration given for VCT services, fear of HIV positive results, and fear of stigma and discrimination. Another study in Bethzatha project indicated that individuals having educational status of secondary school and above, being female, and Christian religion were associated with willingness to take VCT [11-13].

The 2013 Awi Zone Health Department annual report showed that the coverage of VCT utilization was 70\% [14]. However, teachers were very few in the utilization of VCT services as compared to other professionals. There was scarcity of such studies conducted in Awi Zone especially in higher professional population groups. Hence, this study was initiated to fill the knowledge gap in identifying the factors that affect the acceptability of VCT services among teachers for exerting multidirectional HIV/AIDS prevention and controlling efforts, responsible professionals for creating human capital for next generation, involving shaping of school adolescents. Furthermore, the findings of this study were intended to help policy makers and planners as an input for their future program planning by identifying factors associated with VCT utilization among secondary school teachers.

This study was intended to determine magnitude of VCT service utilization and assess the associated factors among secondary school teachers in terms of sociodemographic, cognitive, and service delivery factors (Figure 1).

Note. Respondents were considered to have comprehensive knowledge about HIV/AIDS if they knew about the three HIV prevention methods (abstinence, being faithful to one HIV uninfected partner, and condom use).

\section{Methods and Materials}

2.1. Study Period and Setting. A cross-sectional study was conducted in secondary school teachers from September to October 2014 in Awi Zone. Awi Zone, one of the eleven zones in Amhara National Regional State, located $447 \mathrm{~km}$ away from Addis Ababa at north west direction along Bahir Dar highway. There were 13 secondary schools (7 high schools and 6 preparatory schools) and 1004 teachers in the zone in all its 11 district administrations. The potential health service coverage by public health facilities of the zone was $98 \%$. VCT, PMTCT, and ART services were also given in 28, 15, and 9 health centers, respectively.

2.2. Study Population. All secondary school teachers, who worked at the time of the study, were included in the study whereas unconsciously sick ones at the specified period were excluded.

2.3. Sample Size Determination and Sampling Technique. The number of study participants required for the study was determined using single population proportion formula in consideration of $95 \%$ confidence level, $5 \%$ precision, design effect of 2, 10\% nonresponse rate, and $46.3 \%$ practice rate of VCT among teachers obtained from pervious study in Ethiopia [7] from a source population of 1004. The calculated final sample size was 609.

A two-stage sampling procedure was employed in order to get representative sample size from the source population. In the first stage, seven out of 13 secondary schools (6 preparatory and 7 high schools) were selected using lottery method simple random sampling technique. The determined sample size was allocated to each school proportional to the size of study population. Secondly, to pick individual participant from each selected school, lists of teachers were taken from the school Administration Office and codes were given. Then the required sample sizes were selected using systematic random sampling. To determine the $K$ th value for systematic random sampling a total number of teachers were divided into each cluster sample size. The first participant was selected using lottery method simple random sampling technique.

2.4. Data Collection Instruments and Procedure. The data were collected using face-to-face structured questionnaire adopted from HIV/AIDS behavioral surveillance survey (BSS) [15] and demographic health survey (DHS) [16]. The questionnaire was initially prepared in English, translated to Amharic version and back to English to ensure its consistency and comparability. Pretest was conducted on 30 secondary 


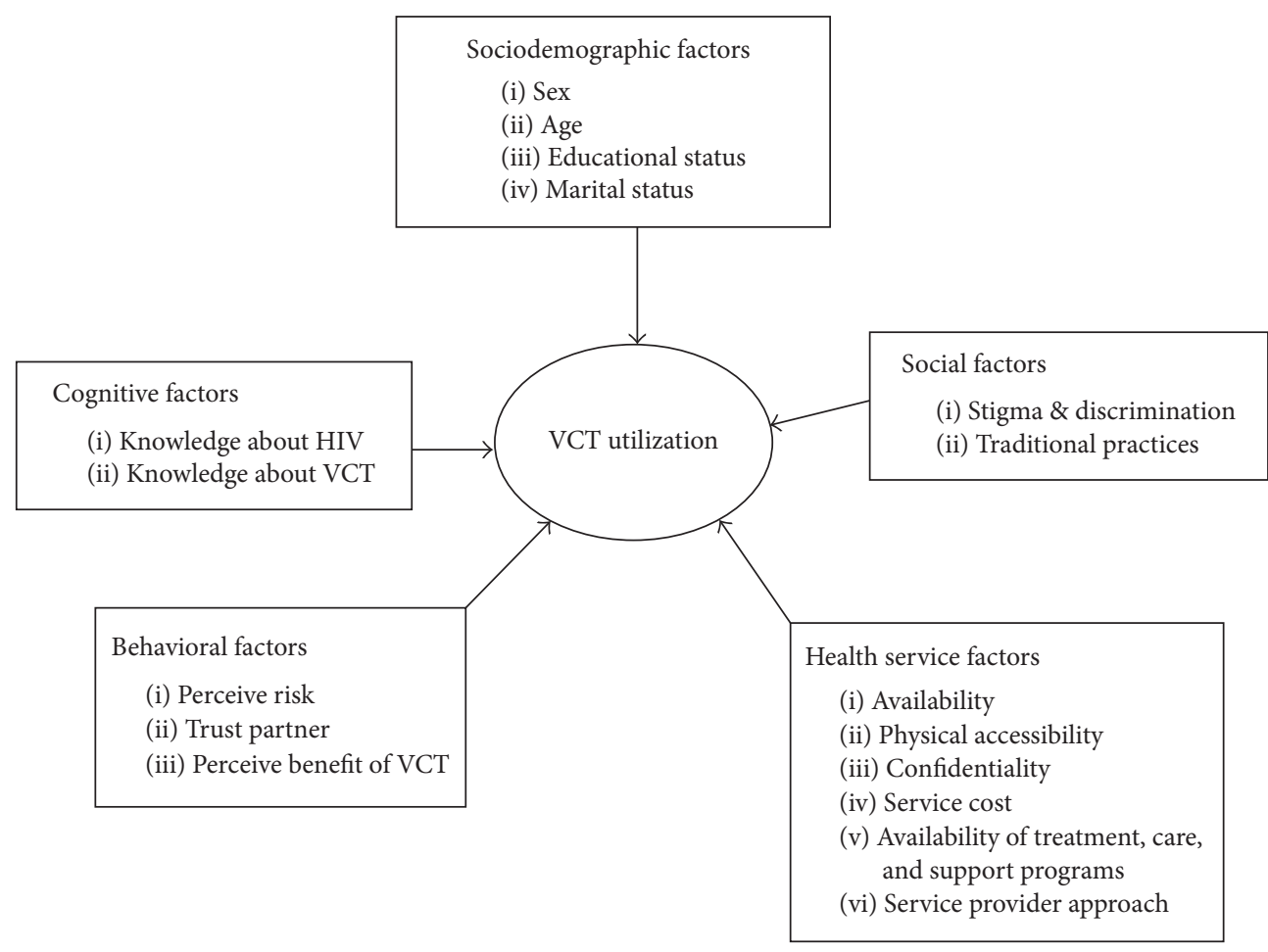

FIgURE 1: Conceptual framework for factors influencing VCT service utilization among secondary school teachers in Awi Zone, Amhara Region, 2014.

school teachers out of the study area to prevent information contamination. After the necessary modifications were made for ambiguous questions the actual data collection had taken place among study subjects.

Two supervisors and five data collectors, who have Bachelor of Science and diploma level nurses, respectively, were recruited and trained about the process of data collection for two days and collected the data.

2.5. Data Management and Analysis. Precoded data were entered and cleaned using Epi-info version 3.5.1 software. The entered data were exported to SPSS version 16 software and analysis was done. The data were presented using description, tables and graphs. Presence and strength of associations between dependent and independent variables were determined using odds ratio with $95 \%$ CI. Multivariable model logistic regression was employed to control possible confounding effects among variables that had $p$ value $<0.2$ at bivariate regression.

2.6. Ethical Consideration. Ethical clearance was obtained from ethical clearance committee, Addis Continental Institute of Public Health, and University of Gondar joint MPH program. Permission letters were obtained from Amhara National Regional State Education Bureau and other substructures of education sector wrote a permission letter to study institutions accordingly. Verbal informed consent of the study participants was secured after explaining the purpose of the study. All the communications with study subjects were made with strict privacy and confidentiality. To keep confidentiality no individual identifiers were used and the collected data were put in lockable cupboard and password protected computer.

\section{Results}

3.1. Sociodemographic Characteristics. A total of 588 individuals with a response rate of $96.5 \%$ participated in this study. The mean age of study subjects was 29.8 ranging from 20 to 55 years with standard deviation of 6.3. Most of the respondents were males $(85.2 \%)$ and $55 \%$ were single in marital status. The majority (94\%) was first degree and most $(86.7 \%)$ were Christian by religion. More than half of (52.4\%) respondents were Agew by ethnicity (Table 1).

3.2. Sexual History of Study Subjects. Four hundred eightynine $(83.1 \%)$ reported that they ever had sex at the time of the survey. From those who had sexual experience, 248 (50.7\%) reported that they had more than one sexual partner. Among them, $230(92.7 \%)$ reported that they had used condom (Table 2).

3.3. Knowledge, Attitude, and Practice on VCT. Regarding HIV counseling and testing services all have heard about confidential VCT services. The common sources of information about HIV counseling and testing services reported by secondary school teachers were mass media 525 (89.3\%) 
TABLE 1: Sociodemographic characteristics of secondary school teachers in Awi Zone, Amhara Region, Ethiopia, 2014.

\begin{tabular}{lccc}
\hline Characteristics & Category & Frequency & Percent \\
\hline \multirow{2}{*}{ Sex } & Male & 501 & 85.2 \\
& Female & 87 & 14.8 \\
Age group & $20-29$ & 346 & 58.8 \\
& $30-39$ & 191 & 32.5 \\
Marital status & $40-55$ & 51 & 8.7 \\
& Single & 329 & 55.9 \\
Educational level & Married & 249 & 42.4 \\
& Wirst degree and above & 553 & 94.0 \\
& Diploma and certificate & 35 & 6.0 \\
Religion & Orthodox Christian & 510 & 86.7 \\
& Muslim & 58 & 9.9 \\
& Others & 20 & 3.4 \\
Ethnicity & Agew & 308 & 52.4 \\
& Amhara & 252 & 42.8 \\
& Others & 28 & 4.8 \\
Monthly income & 1000-2000 birr & 12 & 2.0 \\
& >2000 birr & 224 & 59.9 \\
& & &
\end{tabular}

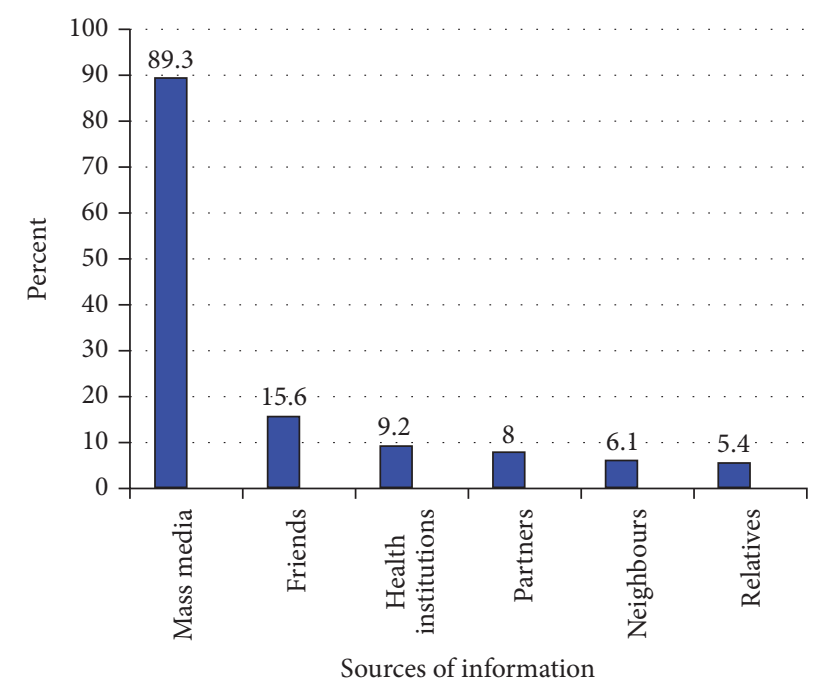

Figure 2: Sources of information about VCT among secondary school teachers in Awi Zone, Amhara Region, 2014.

and the other $63(10.7 \%)$ were from health institutions, friends/peers, relatives, spouse, and neighbors (Figure 2).

Of the participants who had awareness about VCT services, 575 (100\%) knew that voluntary counseling and testing service is available in their localities. Of them, 425 (72\%) reported that the service process could take more than 30 minutes including walking time to reach the service site while others, $163(28 \%)$ teachers, reported that they could have got the service within less than 30 minutes (Table 3). The main sites stated by teachers to get VCT service other than their localities were the said hospital, 438 (74.5\%), private clinics,
307 (52.2\%), health centers, 233 (39.9\%), family guidance clinics, 208 (35.4\%), and mobile sites, 8 (1.4\%) and those who did not know other sites to get VCT services were 40 (6.8\%).

Seventy-two percent, 472 (72.4\%), of the respondents had good knowledge about VCT. Almost all, 569 (96.7\%), of respondents agreed that HIV counseling and testing service is important and the reasons given for the importance of services were as follows: to know one's own health status, 460 (78.2\%), to protect oneself from being infected, 267 (45.5\%), if positive not to transmit to others, 225 (38.3\%), if positive mothers to protect the child from HIV transmission, 202 $(34.4 \%)$, to choose partner, $173(29.4 \%)$, to plan future life, 235 (40\%), and if positive to get treatment, care, and support services, 7 (1.2\%).

Regarding targets for HIV counseling and testing services, 147 (25\%) said any sexually active person, 144 (24.5\%) anyone expected to be at risk, 135 (22.9\%) those who are to be married, $128(21.8 \%)$ those people who have more than one partner, 107 (18.8\%) partners of commercial sex worker, 68 (11.5\%) people who are sick, and 17 (2.9\%) all people.

Three hundred fifteen (53.6\%; 95\% CI: 49.4\%, 57.7\%) of study subjects ever had HIV test. From those study participants who had HIV test 83 (26.3\%) underwent HIV test before three months, 60 (19.1\%) before six months, 138 (43.8\%) before one year, $13(4.1 \%)$ before two years, $8(2.5 \%)$ before three years, and $13(4.1 \%)$ before four years. Of the HIV tested study subjects, 298 (93.9\%) utilized counseling service. Among these participants 166 (56.3\%), 106 (35.9\%), and $29(9.8 \%)$ had received both pre- and posttest, pretest, and posttest counseling services in that order.

About the service delivery, 281 (89.2\%) study subjects who were tested stated that they were satisfied with the service; $33(10.5 \%)$ claimed that they were not satisfied by the given service. The reasons reported for being satisfied are as follows: $180(57.1 \%)$ quick service, $180(34.3 \%)$ confidentiality, 111 (35\%) privacy, 89 (28.3\%) warm reception, $84(26.7 \%)$ health workers competency, 118 (37.5\%) brief counseling, 80 (25.4\%) free service, and 31 (9.8\%) referral linkage for treatment, care, and support services.

On the other hand, the reason mentioned for dissatisfaction of VCT services were, 18 (90\%), no warm reception, 13 (65\%), lack of confidentiality, 13 (65\%), health workers competency, 7 (35\%), no clear counseling service, 6 (30\%), long waiting time, 5 (25\%), no referral linkage for treatment and other care and support services, and, 4 (20\%), lack of privacy.

3.4. Reasons for HIV Counseling and Testing. Among respondents who utilized HIV counseling and testing services the reasons given for being tested were for knowing selfstatus, 161 (51.1\%), for planning future life, 129 (40.9\%), for premarital cases, 80 (25.4\%), for blood donation, 9 (2.8\%), and for starting antiretroviral treatment, 7 (2.2\%) (Figure 3). On the other hand, respondents' reasons reported for not being tested were fear of result, $80.6 \%$, fear of stigma, $17.2 \%$, and other reasons, $17.2 \%$ (Figure 4 ). 
TABLE 2: Sexual history of secondary school teachers in Awi Zone, Amhara Region, Ethiopia, 2014.

\begin{tabular}{|c|c|c|c|}
\hline Characteristics & Category & Frequency & Percent \\
\hline \multirow{2}{*}{ Ever had sex $(n=588)$} & Yes & 490 & 83.3 \\
\hline & No & 98 & 16.7 \\
\hline \multirow{2}{*}{ Ever had sex with multiple sexual partners in the last five years $(n=489)$} & Yes & 248 & 50.7 \\
\hline & No & 241 & 49.3 \\
\hline \multirow{2}{*}{ Ever used condom with multiple sexual partners in the last five years $(n=248)$} & Yes & 230 & 92.7 \\
\hline & No & 18 & 7.3 \\
\hline \multirow{2}{*}{ How often they used condom with multiple sexual partners $(n=230)$} & Always & 136 & 58.7 \\
\hline & Sometimes & 95 & 41.3 \\
\hline
\end{tabular}

TABLE 3: Knowledge, attitude, and practice of secondary school teachers on VCT, Awi Zone, Amhara Region, Ethiopia, 2014.

\begin{tabular}{|c|c|c|c|}
\hline Characteristics & Category & Frequency & Percent \\
\hline \multirow{2}{*}{ VCT available in your locality } & Yes & 575 & 97.8 \\
\hline & No & 13 & 2.2 \\
\hline \multirow{2}{*}{ Time to take the service } & Less than 30 minutes & 163 & 27.7 \\
\hline & More than 30 minutes & 425 & 72.3 \\
\hline \multirow{2}{*}{ Comprehensive knowledge about VCT } & Good knowledge & 426 & 72.4 \\
\hline & Poor knowledge & 162 & 27.6 \\
\hline \multirow{3}{*}{ VCT mentioned as important $(n=588)$} & Yes & 569 & 96.7 \\
\hline & No & 10 & 1.7 \\
\hline & Neutral & 9 & 1.7 \\
\hline \multirow{2}{*}{ Ever had VCT test $(n=569)$} & Yes & 315 & 53.6 \\
\hline & No & 273 & 46.4 \\
\hline \multirow{2}{*}{ Place where HIV test was performed $(n=315)$} & Government health center & 263 & 83.5 \\
\hline & Other health institutions & 52 & 16.5 \\
\hline
\end{tabular}

VCT: voluntary counseling and testing; HIV: Human Immunodeficiency Virus.

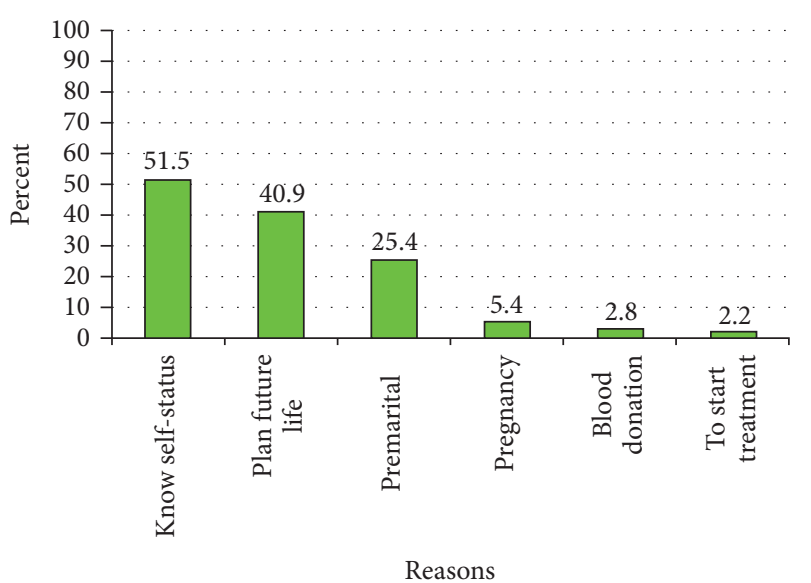

FIGURE 3: Reason mentioned to get tested for HIV among secondary school teachers in Awi Zone, Amhara Region, 2014.

3.5. Factors Associated with VCT Service Utilization. Respondents of age group 20-29 utilized VCT services 3 times better than 40 years and above (AOR: 3.03; 95\% CI: 1.4, 6.13).

Divorced/widowed and married study participants were more than four and two times extra utilizing VCT services than unmarried counterparts (AOR: 4.38; 95\% CI: 1.0, 18.32 and AOR: 2.29; 95\% CI: 1.51, 3.49), respectively. In terms of

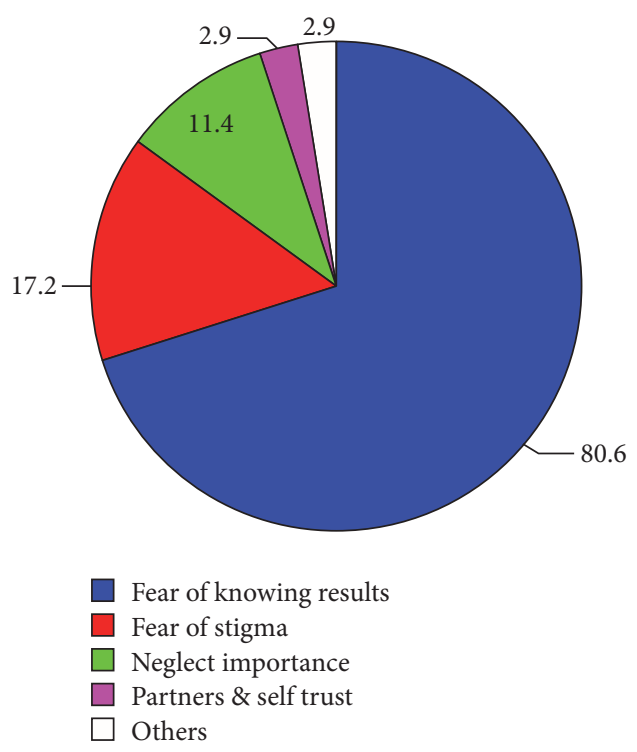

FIGURE 4: Reasons mentioned not to get tested for HIV among secondary school teachers in Awi Zone, Amhara Region, 2014.

education level of respondents who had first degree and above they used VCT services less as compared to the respondents of diploma and certificate holders (AOR: 0.29; 95\% CI: 0.11, 
TABLE 4: Associations of selected sociodemographic variables with VCT service utilization among secondary school teachers in Awi Zone, Amhara Region, Ethiopia, 2014.

\begin{tabular}{|c|c|c|c|c|c|}
\hline \multirow{2}{*}{ Characteristics } & \multirow{2}{*}{ Category } & \multicolumn{2}{|c|}{ Had VCT } & \multirow{2}{*}{ COR (95\% CI) } & \multirow{2}{*}{$\operatorname{AOR}(95 \% \mathrm{CI})$} \\
\hline & & Yes & No & & \\
\hline \multirow{2}{*}{ Sex } & Male & 266 & 235 & $0.88(0.56,1.39)$ & $1.07(0.66,1.74)$ \\
\hline & Female & 49 & 38 & 1 & 1 \\
\hline \multirow{3}{*}{ Age group } & $20-29$ & 201 & 145 & $1.69(0.90,3.18)$ & $3.03(1.40,6.13)^{*}$ \\
\hline & $30-39$ & 91 & 100 & $1.11(0.57,2.16)$ & $1.44(0.76,2.75)$ \\
\hline & $40-60$ & 23 & 28 & 1 & 1 \\
\hline \multirow{3}{*}{ Marital status } & Single & 162 & 167 & 1 & 1 \\
\hline & Married & 146 & 103 & $1.46(1.03,2.07)$ & $2.29(1.50,3.49)^{*}$ \\
\hline & Divorced/widowed & 7 & 3 & $2.41(0.55,11.95)$ & $4.38(1.05,18.32)^{*}$ \\
\hline \multirow{2}{*}{ Educational level } & Above first degree & 286 & 267 & $0.22(0.08,0.57)^{*}$ & $0.29(0.11,0.75)^{*}$ \\
\hline & Diploma and certificate & 29 & 6 & 1 & 1 \\
\hline \multirow{3}{*}{ Religion } & Orthodox & 278 & 232 & 1 & 1 \\
\hline & Muslim & 30 & 28 & $0.89(0.50,1.59)$ & $1.01(0.58,1.78)$ \\
\hline & Others & 7 & 13 & $0.45(0.16,1.23)$ & $0.48(0.18,1.25)$ \\
\hline \multirow{3}{*}{ Monthly income } & $<1000$ birr & 10 & 2 & 1 & 1 \\
\hline & 1000-2000 birr & 196 & 160 & $0.24(0.04,1.21)^{*}$ & $0.47(0.077,2.15)$ \\
\hline & >2000 birr & 109 & 111 & $0.20(0.03,0.99)^{*}$ & $0.37(0.07,2.05)$ \\
\hline
\end{tabular}

*Significantly associated; VCT: voluntary counseling and testing.

0.75). However, VCT service vitalization was not significantly associated $(p>0.05)$ with sex, religion, and income of respondents (Table 4 ).

Respondents who had practiced sexual intercourse utilized VCT services two times greater than those who had not (AOR: 2.25; 95\% CI: 1.09, 4.61). Similarly, the participants who had multiple sexual partners utilized VCT services about 2 times more than those who do not (AOR: 1.96; 95\% CI: 1.37, 2.81) (Table 5). However, significant association was not observed among partners who used condom during intercourse with multiple sexual partners compared to their counterparts.

Knowledge about VCT was significantly associated with VCT service utilization. Respondents who had good knowledge utilized VCT services 3 times higher than those who had poor knowledge about VCT services (AOR: 3.05; 95\% CI: 1.72, 7.21).

Respondents perceived to be discriminated by family and unwilling to disclose themselves utilized VCT services about $22 \%$ and $62 \%$ less than their counterparts (AOR: $0.22 ; 95 \%$ CI: $0.055,1.01$ and AOR: 0.62; 95\% CI: 0.44, 0.88), respectively (Table 6).

\section{Discussion}

VCT is one of those approaches that are adopted at the national level for HIV/AIDS prevention and control strategies. This study tried to look into some of the important factors that affect the utilization of VCT among secondary school teachers in Awi Zone.

In this study we found that the proportion of VCT service utilization was $53.6 \%$, which is still low as compared to VCT service utilized by the general community (70\%) in Awi Zone [14]. This figure is considerably higher when compared to the study conducted in Harari Administrative region and the 2005 BSS-Ethiopia findings which were $46.3 \%$ and $41.3 \%$, respectively $[7,15]$. Similar study conducted among teachers in Tanzania also showed about $20 \%$ of the participants had utilized voluntary testing for HIV [17]. The increased uptake could be due to the intensive advocacy, health education, and expansion of VCT site and other related activities which have been conducted on HIV/AIDS prevention and control interventions assisted by health extension programs.

In this study, teachers aged between 20 and 29 years utilized VCT services 3 times better than 40 years and above. A study conducted among teachers in Tanzania also indicated that teachers who were aged between 21 and 30 years were significantly associated with an increased rate of having been tested for HIV [17]. Another study conducted in Kagera Region, Tanzania, also revealed an increasing tendency for young people to be tested for HIV especially before marriage [18]. Along with our findings, several population based studies conducted in Ethiopia revealed an association between testing for HIV and age; as age increases, the rate of testing for HIV decreases. The significant positive association of the younger age group may be due to the fact that they perceive themselves at risk of HIV infection.

In this study, respondents with education levels of first degree and above used VCT services less than diploma and certificate holders. This finding supported a study conducted in Gonder among different professional and community groups that showed high school teachers were found to have less acceptance of VCT compared with the other community groups [10]. This could be due to the fact that as people's 
TABLE 5: Association of sexual behaviors with VCT service utilization among secondary school teachers in Awi Zone, Amhara Region, Ethiopia, 2014.

\begin{tabular}{|c|c|c|c|c|c|}
\hline \multirow{2}{*}{ Characteristics } & \multirow{2}{*}{ Category } & \multicolumn{2}{|c|}{ Had VCT } & \multirow{2}{*}{ COR $(95 \%$ CI $)$} & \multirow{2}{*}{$\operatorname{AOR}(95 \% \mathrm{CI})$} \\
\hline & & Yes & No & & \\
\hline \multirow{2}{*}{ Ever had sexual intercourse } & Yes & 271 & 219 & $1.52(0.96,2.40)^{*}$ & $2.25(1.09,4.61)^{*}$ \\
\hline & No & 44 & 54 & 1 & 1 \\
\hline \multirow{3}{*}{ Had sex with multiple sexual partners } & Yes & 181 & 112 & $1.51(1.05,2.03)^{*}$ & $1.96(1.37,2.81)^{*}$ \\
\hline & No & 112 & 136 & 1 & 1 \\
\hline & No response & 22 & 25 & $0.54(0.28,1.08)$ & $1.38(0.53,3.67)$ \\
\hline \multirow{3}{*}{$\begin{array}{l}\text { Frequency of condom use during sexual } \\
\text { intercourse with multiple partners }\end{array}$} & Yes & 117 & 133 & $0.54(0.38,0.77)^{*}$ & $0.69(0.24,2.05)$ \\
\hline & No & 176 & 108 & 1 & 1 \\
\hline & No response & 22 & 32 & $0.42(0.22,0.79)^{*}$ & $0.48(0.27,1.12)$ \\
\hline \multirow{3}{*}{$\begin{array}{l}\text { Frequency of condom use with the } \\
\text { multiple sexual partners }\end{array}$} & Always & 69 & 66 & 1 & 1 \\
\hline & Sometimes & 50 & 65 & $0.69(0.41,0.41)$ & $0.5(0.31,0.8)$ \\
\hline & No response & 143 & 64 & $1.45(0.49,4.3)$ & $0.5(0.31,0.8)$ \\
\hline
\end{tabular}

* Significantly associated; VCT: voluntary counseling and testing.

TABLE 6: Association of knowledge, attitude, and practices towards VCT service utilization, among secondary school teachers in Awi Zone, Amhara Region, Ethiopia, 2014.

\begin{tabular}{lccccc}
\hline \multirow{2}{*}{ Characteristics } & Category & \multicolumn{2}{c}{ Had VCT } & Crude OR (95\% CI) & Adjusted AOR (95\% CI) \\
\hline Educational level & & Yes & No & & \\
& Above first degree & 286 & 267 & $0.22(0.08,0.57)^{*}$ & $0.16(0.17,2.42)$ \\
Knowledge of VCT & Diploma and certificate & 29 & 6 & 1 & 1 \\
& Poor knowledge & 51 & 111 & 1 & 1 \\
Unwillingness to disclose HIV test results for anyone & Good knowledge & 246 & 180 & $2.97(1.99,4.45)^{*}$ & $3.05(1.72,7.21)^{*}$ \\
& Yes & 20 & 82 & $0.16(0.09,0.27)^{*}$ & $0.22(0.055,1.01)$ \\
Attitude of discriminating by family & No & 295 & 191 & 1 & 1 \\
& Yes & 127 & 142 & $0.62(0.44,0.88)^{*}$ & $1.26(0.54,2.79)$ \\
\hline
\end{tabular}

VCT: voluntary counseling and testing; HIV: Human Immunodeficiency Virus; ${ }^{*}$ significantly associated.

knowledge increases about the serious health consequences to the extent of death and the society's reaction to the disease, people could decline to accept VCT despite good knowledge. On the other hand, the study conducted in Tanzania has showed teachers who had a college or university education have been tested for HIV greater than those who had secondary or primary education [17]. The increased uptake of VCT utilization among Tanzanian teachers might be due to the fact that in urban areas those with higher levels of education anticipated reactions of HIV/AIDS related stigma and discrimination less.

Married individuals showed utilizing VCT services 2 times more than unmarried counterparts. Moreover, those who were divorced/widowed utilized VCT services 4 times more than unmarried counterparts. Similar findings were reported from the study conducted in North Wollo Zone, Amhara Region, and in Rakai, Uganda [19, 20]. Individuals who had practiced sex ever and had multiple sexual partners were also depicted to utilize VCT services 2 times more than those who had not. Parallel finding was also reported from a study conducted among 15-49-year age group in Mersa
Town of North Wollo Zone, Ambo and Bahir Dar University Students $[19,21,22]$. This might be due to the fact that those who had practiced sex with multiple sexual partners perceived that HIV is transmitted through high-risk sexual practices.

The present study indicated that individuals who had good knowledge about VCT were three times more likely to utilize VCT service than those who had not. Similar finding was reported from a study among Debre Markos University students [23]. In contrast to this, a study in Harari among teachers indicated that knowing about VCT was not significantly associated with utilization of VCT [7]. This might be because knowledgeable individuals might perceive the benefits gained from being tested for HIV at this time.

In this study individuals with discriminating attitude and fear of stigma were less likely to utilize VCT service than those who had not such perceptions. This finding is inconsistent with other study findings $[19,24,25]$. This could be due to the fact that many years of social mobilization, extensive education, and counseling bring behavioral change on stigma and discrimination attitude. 
The limitation of this study was confined to one zone which may not represent other zones in the region as well as in Ethiopia.

\section{Conclusions and Recommendation}

VCT utilization rate among teachers was still low. Therefore, strengthening coordinated efforts for convincing teachers to perceive their risk behavior and to utilize VCT service is recommended with a special attention to educational level holders of first degree and above who utilized VCT less.

Focused group appropriate activities are necessary using local resources like school community conversation and HIV/AIDS clubs that will bring behavioral change regarding utilization of VCT service to sustain more utilization of VCT among age groups 20-29, those being married and windowed/divorced, those having good knowledge about VCT, and those who had ever sexual intercourse.

\section{Conflicts of Interest}

The authors declare that there are no conflicts of interest regarding the publication of this paper.

\section{Authors' Contributions}

Woudneh Gereme Desta and Kelemu Dessie Bizuneh designed the study and collected data. Woudneh Gereme Desta, Mulusew Alemneh Sinishaw, and Kelemu Dessie Bizuneh performed analysis and wrote the manuscript. All authors read and agreed on the final manuscript submitted.

\section{Acknowledgments}

First and foremost the authors would like to acknowledge Amhara National Regional State Health Bureau, Awi Zone Health Department, Awi Zone Education Department, and all Awi Zone secondary schools for their unreserved support and Amhara National Regional State HAPCO for the financial support of this study. Their heartfelt thanks go to Professor Meaza Demissie, Ato saketa Borru, Dr. Abebe Eshetu, and Miss Banchayehu Atakilt for their technical support. They would also like to extend their thanks to the study participants, without whom the study would not have been a reality. Finally they are interested in acknowledging data collectors and supervisors who provided their devotion to the successful completion of the field activities.

\section{References}

[1] Ministry of Health, National Guide Lines for Voluntary HIV Counseling and Testing in Ethiopia, Ministry of Health, Addis Ababa, Ethiopia, 2007, http://www.ilo.org/wcmsp5/groups/public/—ed_protect/-protrav/_ilo_aids/documents/legaldocument/wcms_125384.pdf.

[2] E. O. Ogunbodede, "HIV/AIDS situation in Africa," International Dental Journal, vol. 54, no. 6, supplement 1, pp. 352-360, 2004.
[3] UNAIDS, "UNAIDS report on the Global AIDS epidemic 2010," http://www.unaids.org/globalreport/Global_report.htm.

[4] "Global information and advice on HIV \& AIDS: HIV and AIDS in Sub-Saharan Africa Regional Overview," 2013, http:// www.avert.org/professionals/hiv-around-world/sub-saharan-africa/overview.

[5] Federal Democratic Republic of Ethiopia, Report on Progress Towards Implementation of the Declaration of Commitment on HIV/AIDS, HAPCO, Addis Ababa, Ethiopia, 2005, http://data .unaids.org/pub/Report/2006/2006_country_progress_report_ ethiopia_en.pdf.

[6] Federal Democratic Republic of Ethiopia/Federal HIV/AIDS Prevention and Control Office, Report on Progress Towards Implementation of the Declaration of Commitment on HIV/AIDS, Federal HIV/AIDS Prevention and Control Office, Addis Ababa, Ethiopia, 2010, http://data.unaids.org/pub/Report/2010/ ethiopia_2010_country_progress_report_en.pdf.

[7] S. Omer and J. Haidar, "VCT uptake and associated factors among teachers from Harari Administrative Region," Ethiopian Journal of Health Development, vol. 23, no. 3, 2010.

[8] A. Asmelash, Assessment of HIV/AIDS related mortality among primary and secondary school teachers in Addis Ababa, using verbal Autopsy [MPH thesis], Addis Ababa University, Addis A baba, Ethiopia, 2004, http://etd.aau.edu.et/bitstream/123456789/ 8482/1/Abebe\%20Asmelash.PDF.

[9] Federal Ministry of Health/Federal HIV/AIDS Prevention and Control Office, AIDS in Ethiopia: Sixth Report, Federal Ministry of Health/Federal HIV/AIDS Prevention and Control Office, Addis Ababa, Ethiopia, 2006, http://www.etharc.org/aidsineth/ publications/AIDSinEth6th_en.pdf.

[10] M. Admassu and Y. Fitaw, "Factors affecting acceptance of VCT among different professional and community groups in North and South Gondar Administrative zones, north west Ethiopia," Ethiopian Journal of Health Development, vol. 20, no. 1, pp. 2431, 2006.

[11] UNAIDS, "Voluntary counseling and testing (VCT): technical update," 2000, http://data.unaids.org/Publications/IRC-pub01/ jc379-vct_en.pdf.

[12] E. Mulugeta, "Socio demographic characteristics, sexual behavior, and reasons for attending VCT service at Bethzatha VCT project," EPHA Abstract 5, 2003.

[13] D. Zerihun, "Trends of HIV infection and profiles of voluntary HIV counseling and testing (VCT) acceptance in seven branch clinics of the Family Guidance Association of Ethiopia," in Proceedings of the 14th EPHA Annual Public Health Conference, Addis Ababa, Ethiopia, October 2003.

[14] Awi Zone Health Department, "Zonal Health Department Annual Report," 2013.

[15] G. Mitike, T. Mekonnen, R. Ayele et al., HIV/AIDS Behavioral Surveillance Survey (BSS), Round Two, Federal Ministry of Health, Addis Ababa, Ethiopia, 2005, http://www.etharc.org/ resources/download/view.download/33/50.

[16] CSA and ICF International, Ethiopia Demographic and Health Survey 2011, Central Statistical Agency and ICF International, Addis Ababa, Ethiopia, 2012, http://www.unicef.org/ethiopia/ ET_2011_EDHS.pdf.

[17] D. C. Kakoko, W. L. Lugoe, and G. T. Lie, "Voluntary testing for HIV among a sample of Tanzanian teachers: a search for sociodemographic and socio-psychological correlates," AIDS Care, vol. 18, no. 6, pp. 554-560, 2006.

[18] J. Lugalla, M. Emmelin, A. Mutembei et al., "Social, cultural and sexual behavioral determinants of observed decline in HIV 
infection trends: lessons from the Kagera Region, Tanzania," Social Science and Medicine, vol. 59, no. 1, pp. 185-198, 2004.

[19] S. Bekele, Assessment of Voluntary HIV Counseling and Testing (VCT) Service Utilization Among 15-49 Years Age Group, AAU, Amhara Region, Ethiopia, 2007, http://etd.aau.edu.et/ handle/123456789/3015.

[20] J. K. B. Matovu, R. H. Gray, F. Makumbi et al., "Voluntary HIV counseling and testing acceptance, sexual risk behavior and HIV incidence in Rakai, Uganda," AIDS, vol. 19, no. 5, pp. 503511, 2005.

[21] G. Endazenaw Bekele, K. Kensa, M. Abebe, and K. T/Mariam, "Assessment of Knowledge, Attitude, Practice and Determinants of VCT utilization for HIV/AIDS among ambo university students, West Shoa Zone, Oromia Region, Ethiopia: Cross Sectional Study," Science Journal of Public Health, vol. 3, no. 2, pp. 259-264, 2015.

[22] G. Fikadie, M. Bedimo, and Z. Alamrew, "Prevalence of voluntary counseling and testing utilization and its associated factors among bahirdar university students," Advances in Preventive Medicine, vol. 2014, Article ID 906107, 9 pages, 2014.

[23] G. Tsegay, M. Edris, and S. Meseret, "Assessment of voluntary counseling and testing service utilization and associated factors among Debre Markos University Students, North West Ethiopia: a cross-sectional survey in 2011," BMC Public Health, vol. 13, no. 1, article 243, 2013.

[24] S. D. Weiser, M. Heisler, K. Leiter et al., "Routine HIV testing in Botswana: a population-based study on attitudes, practices, and human rights concerns," PLOS Medicine, vol. 3, no. 7, article e261, 2016.

[25] S. C. Kalichman and L. C. Simbayi, "HIV testing attitudes, AIDS stigma, and voluntary HIV counselling and testing in a black township in Cape Town, South Africa," Sexually Transmitted Infections, vol. 79, no. 6, pp. 442-447, 2003. 


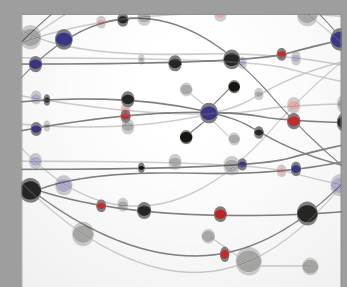

The Scientific World Journal
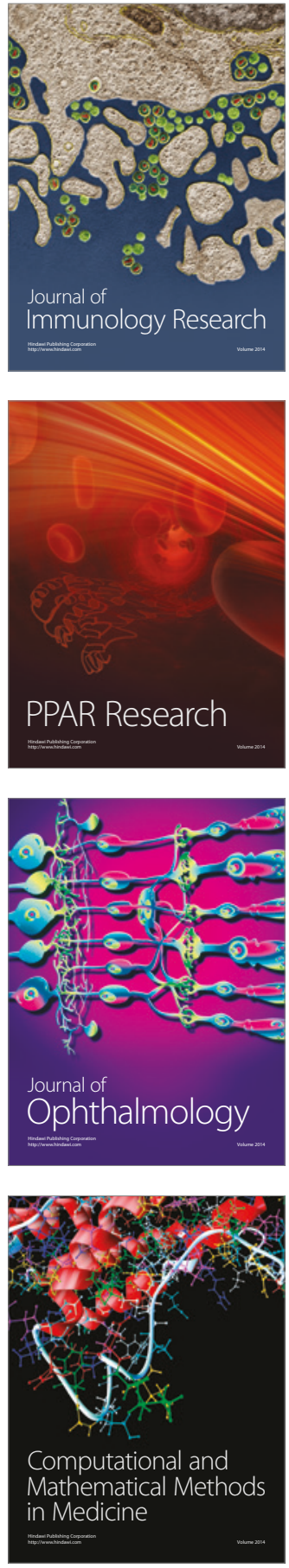

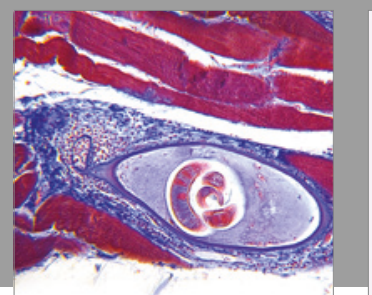

Gastroenterology Research and Practice
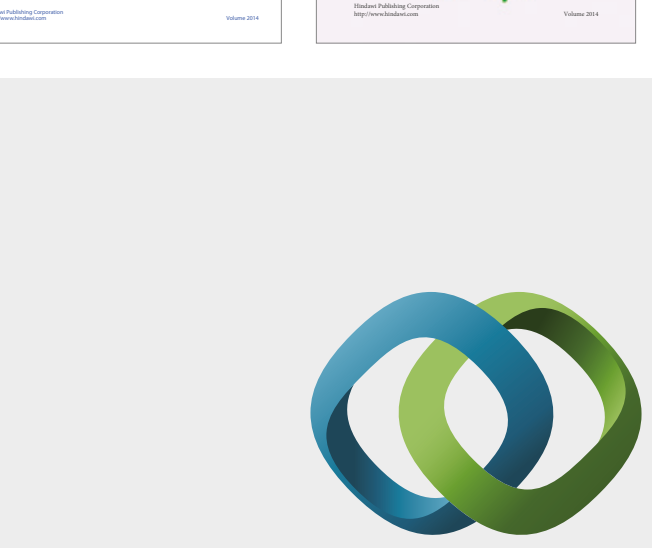

\section{Hindawi}

Submit your manuscripts at

https://www.hindawi.com
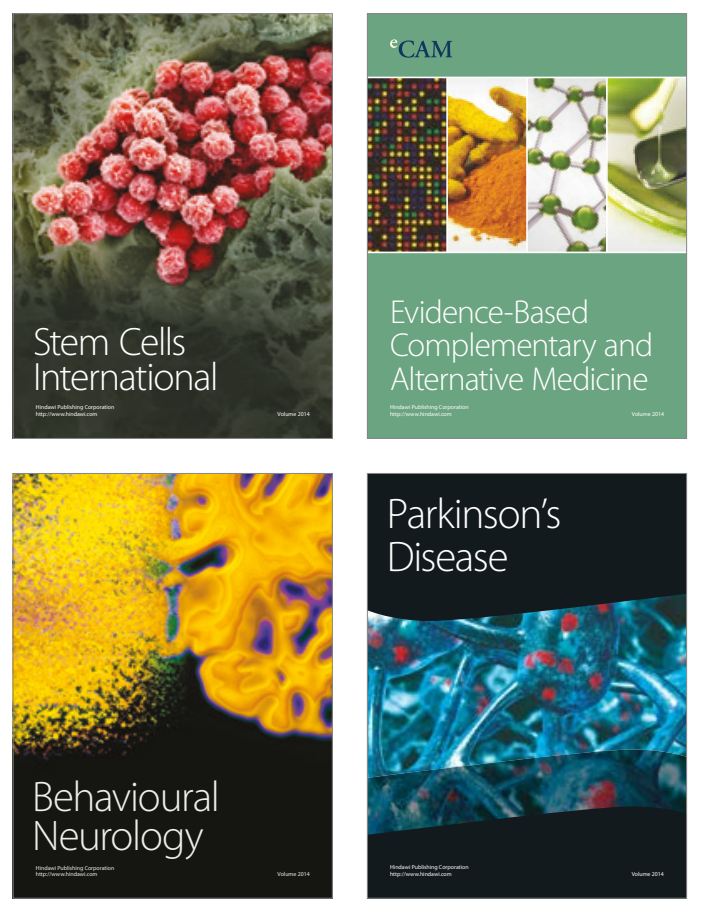
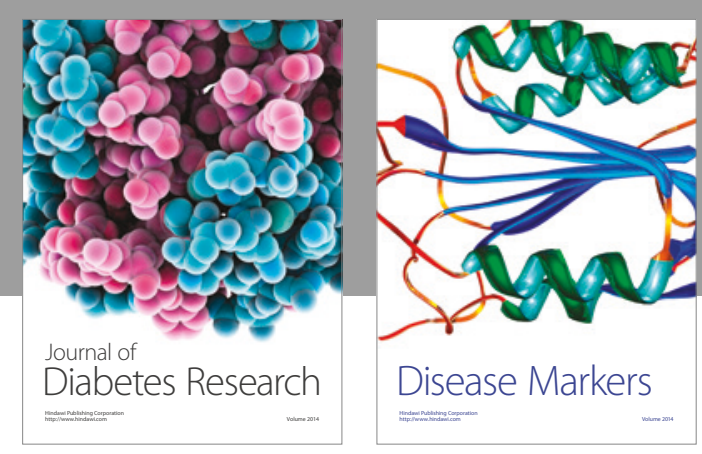

Disease Markers
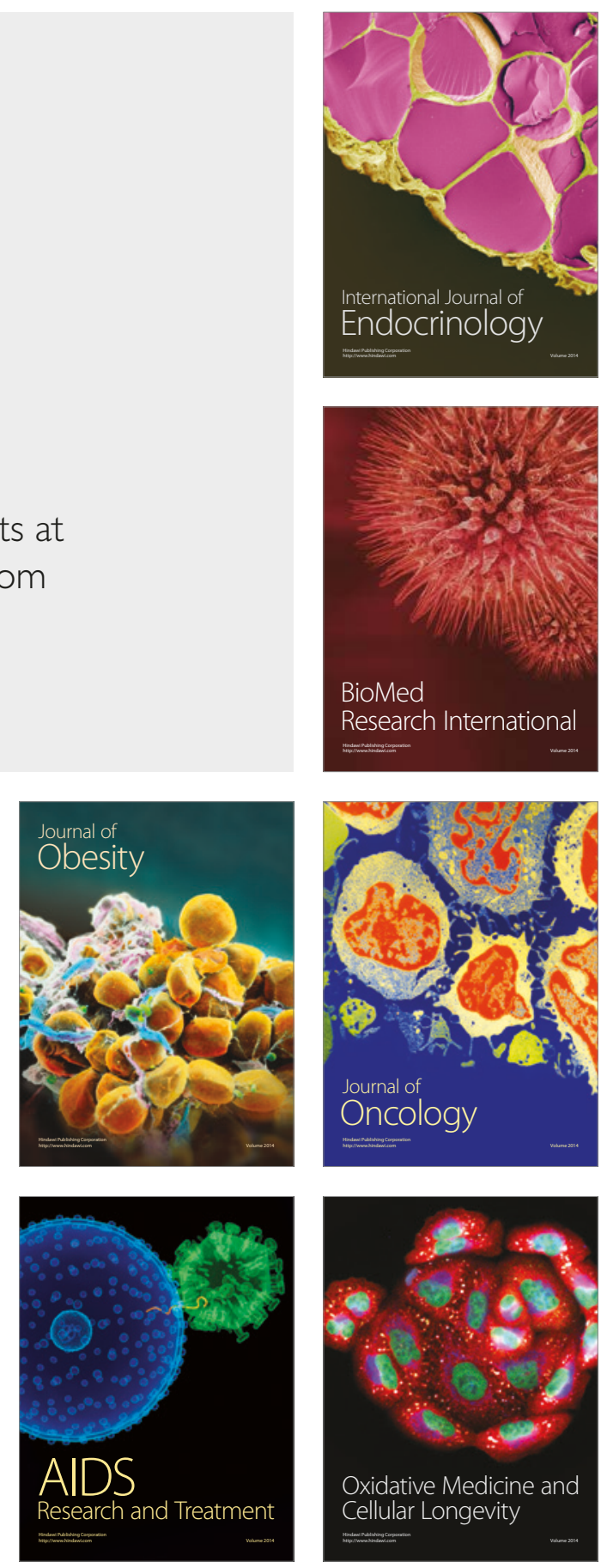